\title{
O USO DE COMPOSTAGEM DOMÉSTICA NA PRODUÇÃO DE ADUBO PARA HORTAS DOMICILIARES
}

\author{
THE USE OF HOUSEHOLD COMPOSTING IN HOUSEHOLD FERTILIZER PRODUCTION
}

\author{
PALOMA DAYCY MENDES SILVA| FACULDADE PITÁGORAS \\ MARILENA CHAVES SILVA | FACULDADE PITÁGORAS \\ SCARLETH KAROLYNE VIEIRA LEITÃO |FACULDADE PITÁGORAS \\ ANA VALÉRIA PIRES MUNIZ | FACULDADE PITÁGORAS
}

\begin{abstract}
RESUMO
Este trabalho vem apresentar um sistema de maturação de resíduos orgânicos produzidos em um domicilio, a pesquisa possui como principais objetivos a construção de uma composteira doméstica de pequeno porte com por meio de materiais de fácil alcance e com baixo valor econômico, separação dos resíduos orgânicos originados pela família responsável pela residência onde será instalada a composteira, acompanhamento do processo de decomposição desses resíduos após os mesmos serem colocados na composteira e após sessenta dias, período necessário para que o adubo esteja pronto para uso, utilizá-lo em uma horta doméstica localizada na mesma residência. O projeto foi desenvolvido em três etapas, a primeira etapa realizou-se uma revisão bibliográfica, a fim de levantar informações necessárias acerca da construção de uma composteira adaptada a ambientes domésticos, pesquisa da qual permitiu construir uma composteira adaptada a partir de uma manual da Empresa Brasileira de Pesquisa Agropecuária - EMBRAPA, a segunda etapa consistiu na construção da própria composteira doméstica em conjunto com a separação dos resíduos orgânicos, a terceira etapa foi o acompanhamento da decomposição desses resíduos e a posterior utilização do adubo na horta domiciliar, após a adubação de uma parte da horta, houve o acompanhamento do desenvolvimento das plantações que receberam o adubo das que não receberam.
\end{abstract}

PALAVRAS CHAVE: Compostagem; Adubo orgânico. Resíduos orgânicos.

\begin{abstract}
This work comes to present a system of maturation of organic waste produced in a household, the research has as its main objectives the construction of a small domestic composter using easily accessible materials with low economic value, separation of organic waste originated by the family responsible for the residence where the composer will be installed, process monitoring decomposition of these residues after they are placed in the compost and after sixty days, period necessary for the fertilizer to be ready for use, use it in a domestic garden located in the same residence. The project was developed in three steps, the first step was a bibliographic review, in order to gather necessary information about the construction of a composer adapted to domestic environments, research which allowed to build a composer adapted from a Company manual Brazilian Agricultural Research Corporation - EMBRAPA, the second stage consisted of the construction of the own domestic compost in conjunction with the separation of organic waste, the third stage was the follow-up of the decomposition of these residues and the subsequent use of the fertilizer in the home garden after fertilization. In a part of the garden, the development of the plantations that received the fertilizer of the ones that did not receive was monitored.
\end{abstract}

KEY WORDS: Composting. Organic fertilizer. Organic waste. 


\section{INTRODUÇÃO}

Diante da enorme geração de resíduos orgânicos, um dos grandes desafios para o ser humano é destinação correta. Pois, na maioria das vezes acabam sendo misturados aos demais materiais e encaminhados inadequadamente às disposições finais, causando danos ao meio ambiente (WAGEN, 2010). Atualmente existem no Brasil milhares de residências, o país é fortemente populoso, esse fato permite que a geração desse tipo de resíduo seja ainda mais evidente e grave, uma vez que quanto maior o crescimento populacional maior a demanda por alimentos, assim percebe-se que a problemática dos resíduos orgânicos é global, porém sua amenização pode ser de maneira individual (SILVA, 2003).

Por conseguinte, quando esses materiais não tratados e dispostos inadequadamente, podem gerar problemas ambientais e de saúde pública. Por que, provocam a depreciação da paisagem, odores oriundos da decomposição de restos orgânicos, presença de vetores (moscas, formigas, baratas, ratos, mosquitos) e a presença de chorume que é um líquido com alta carga de matéria orgânica em degradação, que no contato com um corpo hídrico contamina (BENTO, 2013).

Assim, buscando-se uma resolução para a problemática da disposição de resíduos orgânicos em conjunto com demais tipos de resíduos que são coletados pelo poder público municipal, faz-se necessário implementar práticas individuais e rotineiras para que a quantidade resíduo que é destinado a aterros, por exemplo, possa ser diminuída o que auxilia na manutenção e vida útil do aterro sanitário. Dessa maneira, a composteira doméstica fabricada de maneira manual e adaptada a ambientes com pouco espaço surge como uma alternativa para que cada indivíduo possa contribuir de forma eficiente com a problemática.

Ferreira (2013) salienta que a técnica de compostagem domiciliar é uma alternativa de tratamento a ser considerada para a reciclagem de resíduos orgânicos, pois caracteriza-se por ser um processo natural de decomposição biológica, controlável e operado, possibilitando um adubo orgânico de qualidade para as hortas domiciliares. Além da compostagem, o estímulo pela construção de horta dentro dos domicílios é de grande relevância quanto à geração da produção e consumo de alimentos mais saudáveis.

\section{REFERENCIAL TEÓRICO}

A Lei Federal A Lei Federal no 12.305, de 2 de agosto de 2010, em seu art. 30, inciso VII, aborda como uma das destinações finais ambientalmente corretas de resíduos sólidos, a compostagem (BRASIL, 2010). Neste sentido, a conceituação de compostagem, pode ser definida como sendo o processo de produção de adubo a partir da decomposição dos resíduos orgânicos, a qual pode ser realizada em uma residência, por se tratar de um processo simples e em um tempo de obtenção de resultados relativamente curto, em comparação a outros processos de decomposição ou reciclagem de outros resíduos sólidos (ANDREOLI, 2014).

O processo de compostagem é uma atividade simples e intuitiva, pois existente na sociedade há muitos anos, por meio da formação das serapilheiras no solo, a diferença para atualidade é apenas a adaptação e técnicas para melhor obtenção do composto (BRASIL, 2017). Segundo Siqueira (2016), quando ocorre a decomposição da matéria orgânica com a presença do oxigênio, em uma determinada temperatura ambiente e umidade, tende-se a formação de vários microrganismos atuando no composto, quebrando moléculas, liberando calor, gás carbônico e água. $O$ processo supracitado é um produto estável e rico em matéria orgânica processo natural.

O resultado da decomposição da matéria orgânica é o composto orgânico, altamente nutritivo para os organismos presentes no solo, contribuindo para a estrutura e desenvolvimento das plantas, no processo de absorção de água e nutrientes (macro- N, P, K, Ca e Mg; e micro- Bo, $\mathrm{Cl}, \mathrm{Cu}, \mathrm{Co}, \mathrm{Na}$ ),dessa forma reduz a erosão provocada pelas chuvas no solo (FERREIRA et al, 2013).

Segundo Andreoli (2014), o processo de compostagem pode ser realizado através do cumprimento de etapas pré-definidas, sendo elas: a escolha de um local da residência, em que o piso esteja compactado para evitar a infiltração de chorume, seco, fresco, protegido da insolação direta e da chuva; colocar no local definido, uma camada de $5 \mathrm{~cm}$ de resíduos compostáveis do tipo marrom, como palha ou folhas; sobre ela colocar outros resíduos orgânicos de decomposição rápida, como cascas de alimentos; polvilhar cerca de $5 \mathrm{~cm}$ de terra ou sobrepor nova camada de resíduos compostáveis marrons; uma vez por semana revolver e molhar o composto.

Os resíduos orgânicos compostáveis são classificados em dois grupos: os castanhos e os verdes. A subdivisão dessa grande classe de resíduos ocorre devido a características específicas, como a proporção de materiais inorgânicos como carbono e nitrogênio em sua composição, teor de umidade e velocidade de decomposição (USP, 2012).

Assim, de acordo com USP (2012), o grupo de resíduos orgânicos castanhos é caracterizado por possuir maior concentração de carbono comparativamente ao nitrogênio, baixo teor de umidade e decomposição lenta. Em contrapartida, o grupo ao quais os verdes pertencem, possui como características a quantidade maior de nitrogênio 
em sua composição, teor de umidade mais alto e decomposição mais rápida em comparação ao grupo de resíduos orgânicos castanhos.

Os resíduos orgânicos possuem grande carga de nutrientes, ao momento que entra em contato com os dos resíduos recicláveis secos aumenta o nível de contaminação e dificulta o processo de triagem do mesmo, por isso que a Política Nacional de Resíduos Sólidos (Lei no 12.305/2010) prevê que somente rejeitos devem seguir para disposição final (BRASIL, 2017). A forma da metodologia aplicada para separação dos resíduos pode proporcionar vantagens econômicas e segurança na formação de adubo orgânico, ou seja, no momento que o material orgânico é gerado deve-se armazenar de maneira correta no recipiente condizente com cada realidade.

De acordo com Sartori (2012), o tempo de decomposição da matéria orgânica está sujeita a diversos fatores descritos abaixo, para obtenção do produto final, ou seja, formação do adubo orgânico.

Umidade: É de acordo com a umidade que é desenvolvida a atividade microbiana, pois o metabolismo e reprodução dos microrganismos dependem da água para se desenvolver. Uma das maneiras de verificar o teor de umidade é apertar o composto com as mãos: se o mesmo tiver uma concentração de água adequada, poderemos sentir a umidade e a agregação do material.

Aeração: O oxigênio é importante para os microrganismos, pois a decomposição é um processo de oxidação biológica das moléculas ricas em carbono, com liberação de energia, a mesma é consumida pelos organismos, e os nutrientes liberados são consumidos pelas plantas.

Temperatura: Um dos fatores de grande relevância no processo de transformação da matéria orgânica é a temperatura do ambiente onde se realiza o processo, pois a forma de armazenamento dos resíduos proporciona elevada temperatura pode chegar à cerca de $80^{\circ} \mathrm{C}$.

Relação Carbono/Nitrogênio: As matérias-primas ricas em nutrientes orgânicos e minerais, que contenham especialmente, relação carbono/nitrogênio $(C / N)$ favorável são as mais recomendáveis para a compostagem. Essa relação deve ser em torno de 30/1, ou seja, que para cada parte de nitrogênio, na forma de estrume, devem estar presentes 30 partes de carbono na forma de palhada, para que a compostagem se realize com eficiência.

Tamanho das partículas: As partículas dos materiais não devem ser muito pequenas, para evitar a compactação durante o processo, comprometendo a aeração.

Sementes, patógenos e metais pesados na compostagem: A presença de sementes de plantas invasoras, pragas, patógenos e metais pesados, que interferem na produção agrícola, são considerados agentes indesejáveis. Utiliza-se o composto no solo, como corretivo orgânico, principalmente em solos pobres em matéria orgânica como os argilosos e arenosos.

Os resíduos orgânicos, que representam cerca de 50\% dos resíduos urbanos gerados no Brasil, tem a particularidade de poderem ser reciclados por meio de processos como a compostagem. O reaproveitamento dos resíduos orgânicos não necessita de grandes exigências tecnológicas ou recursos financeiros para que o processo possa ser realizado com efetividade, ações de educação ambiental tem tido êxito, como forma de empoderar pessoas na reprodução do ciclo da matéria orgânica (BRASIL, 2017).

De acordo com Brasil (2013), 1,5\% dos resíduos orgânicos domiciliares do País são reciclados através da compostagem. Desta forma, a compostagem possibilita o aproveitamento desses resíduos, que representam mais da metade do lixo domiciliar.

Assim a construção de composteiras adaptadas a qualquer tipo de local, funciona como fator atrativo para os indivíduos, estimulando-os a reciclarem os resíduos orgânicos que sobram da sua alimentação, segundo Melo (2014) ao realizar uma pesquisa nesse mesmo contexto, relatou que a maioria dos moradores participantes de pesquisa garantiram que tem interesse em praticarem a separação dos resíduo orgânicos e utiliza-los para a compostagem.

Melo (2014) evidencia ainda que a quantidade de resíduos que era disposta para serem coletados pela Prefeitura Municipal teve uma redução significativa e que os envolvidos no processo da compostagem não encontraram trabaIho ao realizar a prática e no gerenciamento do processo.

No contexto do plantio de tipos de hortaliças com utilização de adubo produzido nesse tipo de composteira, Costa (2018) evidencia que após o plantio com a utilização de adubo produzido domesticamente, constatou-se a abertura de novas folhagem nas plantas após um período de sete dias.

A utilização de composteira com pequeno porte vem sendo estudada por pesquisadores há tempos, o que evidencia a sua fácil capacidade de construção e manutenção, além do que Amorim et al. (2016) explica que durante o processo de compostagem desse tipo, em pequena escala, não foi detectada presença de odores advindos da atividade de decomposição, fato este que evidencia que se bem aplicado, o processo é bem desenvolvido e traz um adubo de qualidade.

A garantia da qualidade da composteira é dada a partir de manutenções realizadas periodicamente, essa manutenção é realizada através de etapas simples, tais como: trituração do resíduo orgânico, disposição do mesmo em 
camadas, acrescentar resto de pó de café a fim de evitar odores, ficar atento ao prazo para o composto está pronto, que é compreendido entre um período de 30 a 60 dias e após pronto, o composto deve ser retirado da composteira (SENAl, 2017).

Chan et al. (2010) ressalta que o tratamento dessa fração de resíduo orgânico por meio de técnicas de compostagem nos domicílios é indispensável para o alcance a eficiência da gestão ambiental por parte dos municípios brasileiros, inclusive com a inclusão da prática no sistema de gestão de resíduos sólidos, uma vez que, grande parte dos municípios brasileiros possuem menos de cinquenta mil habitantes, além do país possuir uma atividade agrícola notória que auxilia no processo de compostagem por meio de grandes indústrias, sendo assim em larga escala.

\section{METODOLOGIA}

O desenvolvimento e aplicação do projeto ocorreu em uma residência situada no município de São Luís - MA, no bairro Divinéia - Olho D'Água, com coordenadas geográficas tem-se 2029'27.42"S e 44013'11.48"W (GOOGLE EARTH, 2019). O presente trabalho foi elaborado em algumas etapas. A primeira etapa consistiu em um levantamento bibliográfico em trabalhos como, monografias, dissertações, artigos, manuais, livros e outros meios que abordem os temas relacionados ao projeto. Esse levantamento serviu de base para a elaboração do projeto e para a análise e discussão dos resultados com o intuito de melhorar projetos já aplicados e comparar os seus dados com os obtidos nesse projeto. Para a confecção da composteira foram feitas algumas adaptações com base em alguns manuais elaborados por autores tais como: Célio oliveira e João Fernandes, com o Manual de compostagem doméstica com minhocas da Editora Egito Comercial (2018), Giovana Aparecida Pereira Bento, com o Manual de vermicomostagem da Universidade Federal do Paraná (2013) dentre outros.

A segunda etapa caracterizou-se na elaboração da composteira doméstica adaptada, que foi desenvolvida tendo como referência o Manual "Como montar uma composteira caseira" da EMBRAPA. Os materiais utilizados foram: 3 baldes de 3,6 L, 1 torneira PVC de $1 / 2,20 \mathrm{~cm}$ de cano PVC cortado ao meio, 1 flange de PVC de $1 / 2,1$ joelho de PVC de 1/2, 10 parafusos de porca, silicone para a vedação, conforme a Figura 1.

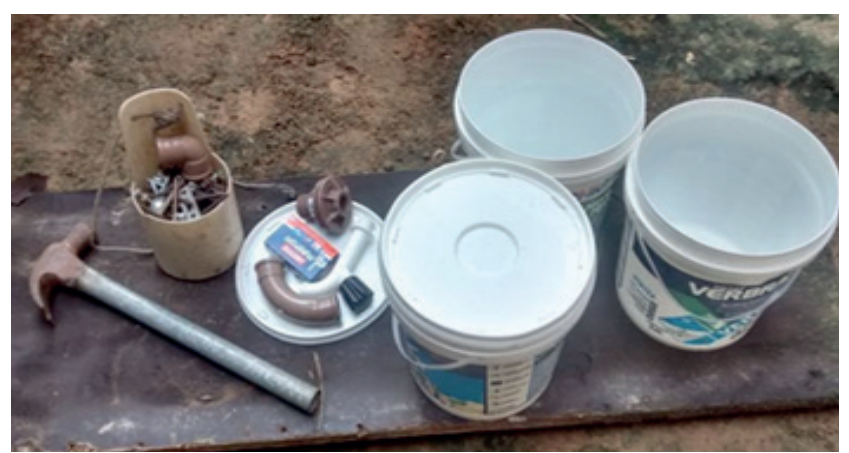

Figura 01 - Materiais utilizados na fabricação da composteira Fonte: Dados da pesquisa, 2019.

A composteira doméstica foi feita da seguinte maneira: no primeiro balde foram feitos vários furos de $6 \mathrm{~mm}$ na tampa, com $2 \mathrm{~cm}$ de distância entre si e foi encaixada a torneira, a $3 \mathrm{~cm}$ da base (Figura 2). No segundo balde cortou-se a sua tampa e o seu fundo, para permitir a passagem dos resíduos (Figura 3). O terceiro balde foi feito um corte no fundo e instalado a flange com os dois pedaços de cano de $20 \mathrm{~cm}$ ligados pelo joelho (Figura 4). Na saída de ar, inserir Algodão / Carvão triturado / Algodão, fazendo um filtro. Os baldes foram empiIhados; entre o primeiro e o segundo balde e o segundo e terceiro balde, foram colocados cinco jogos de parafuso e porca para a junção da tampa com o balde de cima. O silicone foi utilizado para vedação entre os baldes, conforme Figura 5 .

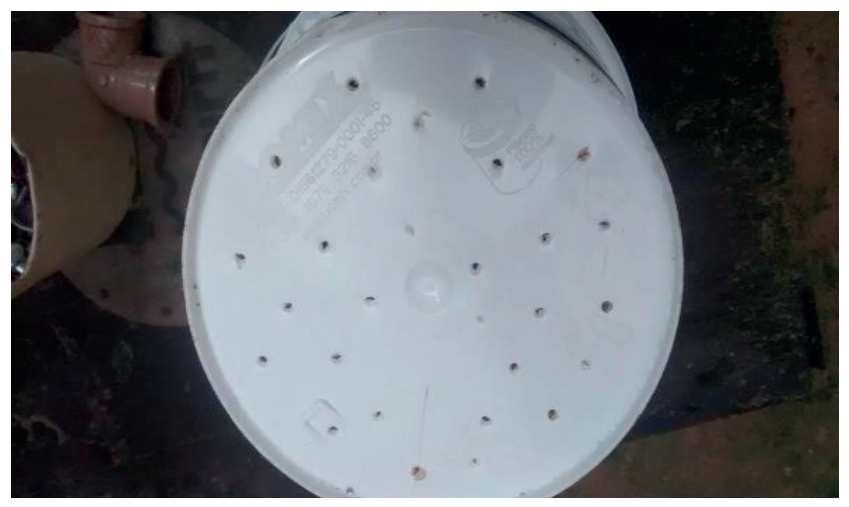

Figura 02 - Furos com diâmetro de $2 \mathrm{~mm}$ feitos no primeiro balde Fonte: Dados da pesquisa, 2019.

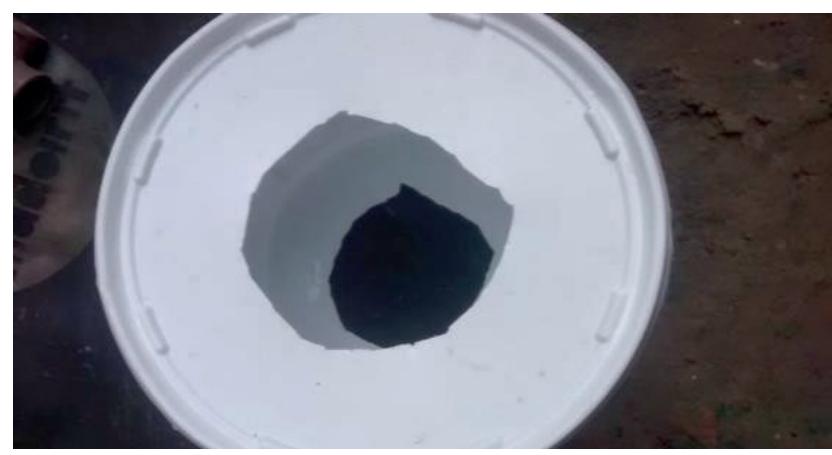

Figura 03 - Abertura feita na tampa e no fundo do segundo balde Fonte: Dados da pesquisa, 2019. 


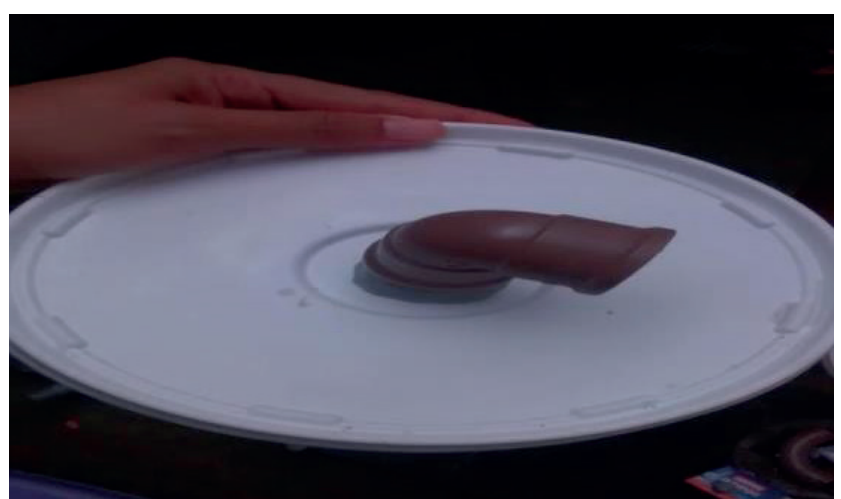

Figura 04 - Instalação de cano no terceiro balde para saída de ar Fonte: Dados da pesquisa, 2019.

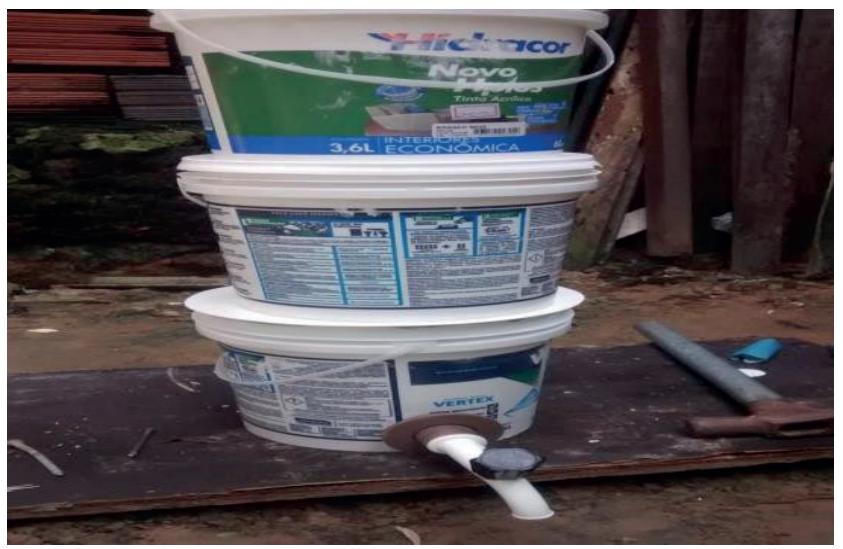

Figura 05 - Baldes empilhados Fonte: Dados da pesquisa, 2019.

A terceira etapa foi composta pela separação dos resíduos orgânicos advindos da alimentação familiar, o tipo de resíduo utilizados foram restos de frutas, legumes, verduras, grãos, sementes, borra de café, sobras de alimentos cozidos ou estragados e casca de ovo (Figura 6). Esses resíduos foram separados e colocados na composteira doméstica, assim ocorreu o monitoramento semanalmente e em torno de 45 dias o adubo ficou pronto.

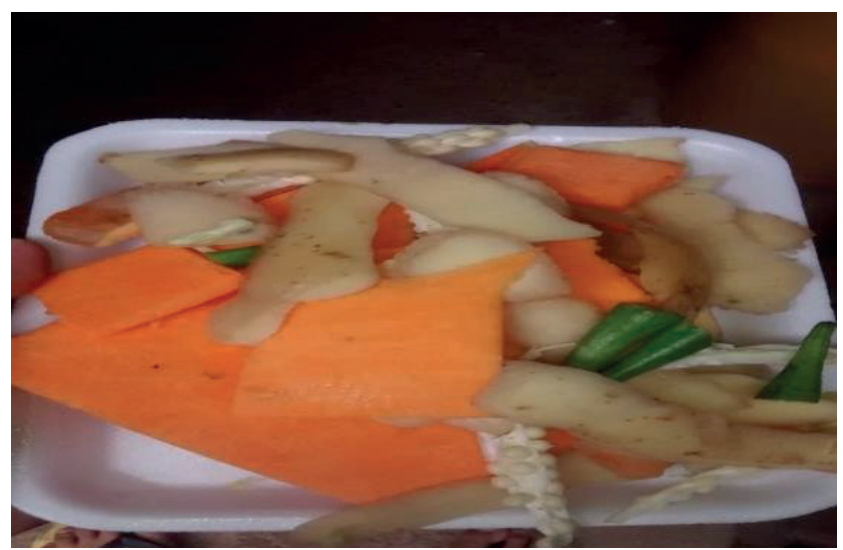

Figura 06 - Separação dos resíduos orgânicos domiciliares Fonte: Dados da pesquisa, 2019.
Após esse período de 45 dias, o adubo foi recolhido e utilizado na horta doméstica existente na residência que o projeto foi implantado. A horta possui plantações pimentão, cebolinha, tomate e ainda outras hortaliças. As sementes utilizadas na horta são provenientes das próprias plantas. Dessa maneira, ocorreu o acompanhamento e manutenção da composteira e a observação no desenvolvimento das hortaliças plantadas na horta após a adubação, e verificou-se um crescimento das hortaliças mais satisfatório após adubação com o composto orgânico, favorecendo assim o fornecimento de hortaliças de qualidade para a residência.

\section{RESULTADOS}

Durante o período de compostagem dos resíduos orgânicos não foi constatado a ocorrência de mau cheiro ou presença de vetores, o que confirma que o processo de maturação se deu sob condições adequadas de aeração, umidade e temperatura. Tais fatores podem ser atribuídos à metodologia utilizada na confecção da composteira doméstica (Figura 7) e na separação dos materiais, utilizando-se apenas resíduos orgânicos, como mostra a (figura 8).

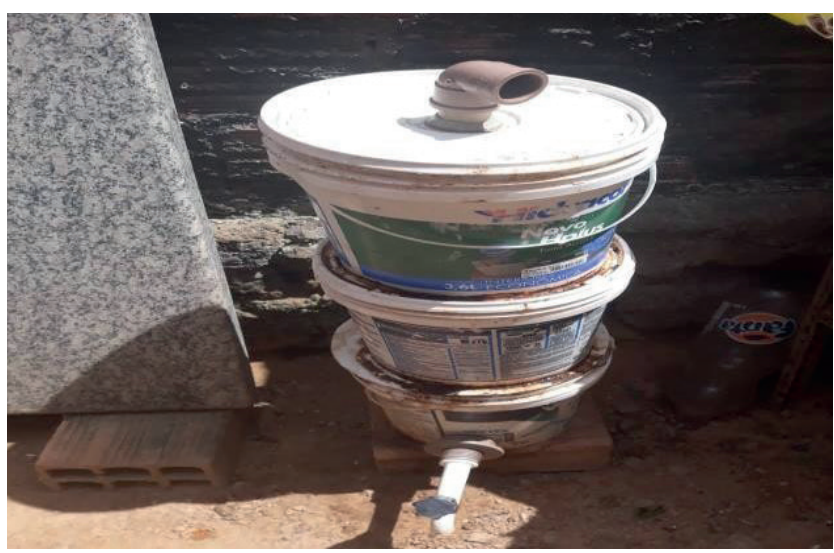

Figura 07 - Composteira Doméstica Fonte: Dados da pesquisa, 2019.

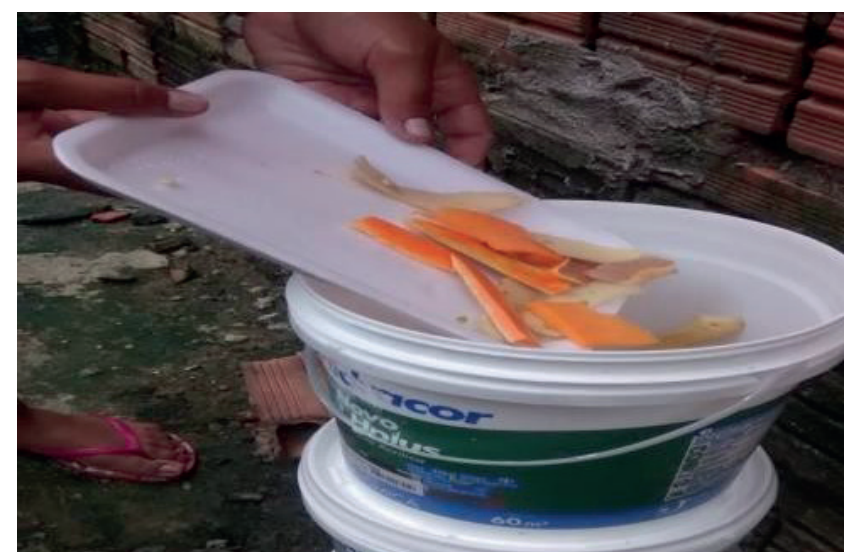

Figura 08 - Resíduos colocados na composteira Fonte: Dados da pesquisa, 2019 
Contudo, ao longo do processo de maturação verificou-se a ocorrência de uma grande diversidade de pequenos artrópodes na massa de resíduos orgânicos sob compostagem (Figura 09). Tal fato, no entanto, foi considerado normal, uma vez que micro-organismos, como fungos, bactérias fazem parte da degradação da matéria durante o processo de compostagem.

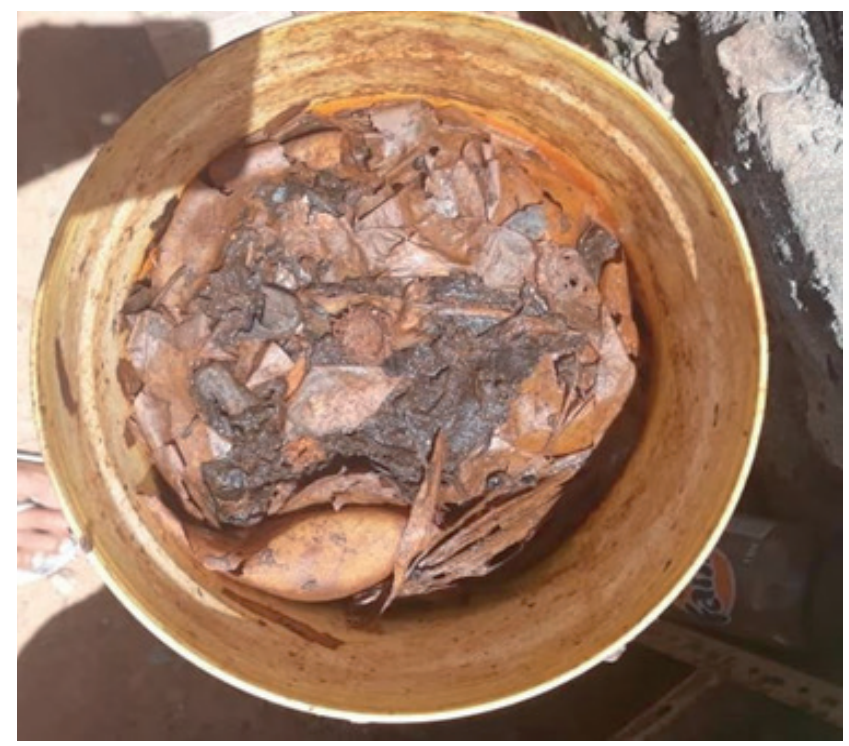

Figura 09 - Processo de maturação na composteira Fonte: Dados da pesquisa, 2019

Diante disso, após 45 dias do início da operação da compostagem, o adubo apresentou-se pronto para utilização. O composto orgânico caracterizou-se por apresentar grau de estabilidade e maturidade, coloração escura, odor de terra, fiabilidade (solto) e ausência de organismos patogênicos, fatores esses que indicaram um adubo orgânico de qualidade, conforme pode-se verificar na Figura 10.

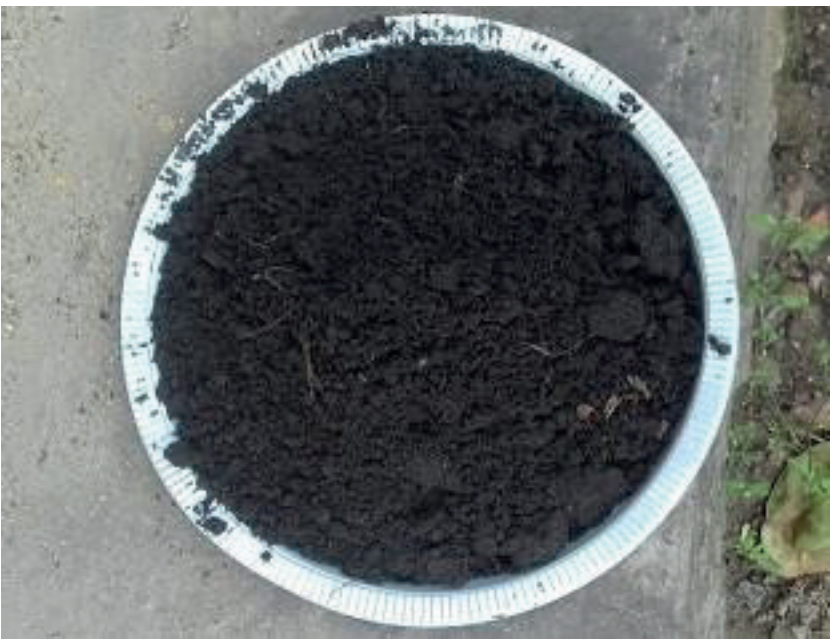

Figura 10 - Adubo orgânico maturado Fonte: Dados da pesquisa, 2019.
A adubação é uma das etapas cruciais para obtenção de produtos de qualidades em hortas domiciliares, pois, permite que as plantas absorvam todos os nutrientes de forma eficaz. A vista disso, após o recolhido do adubo da composteira, ocorreu à utilização do composto orgânico na horta doméstica (Figura 11) existente na residência que o projeto foi implantado.

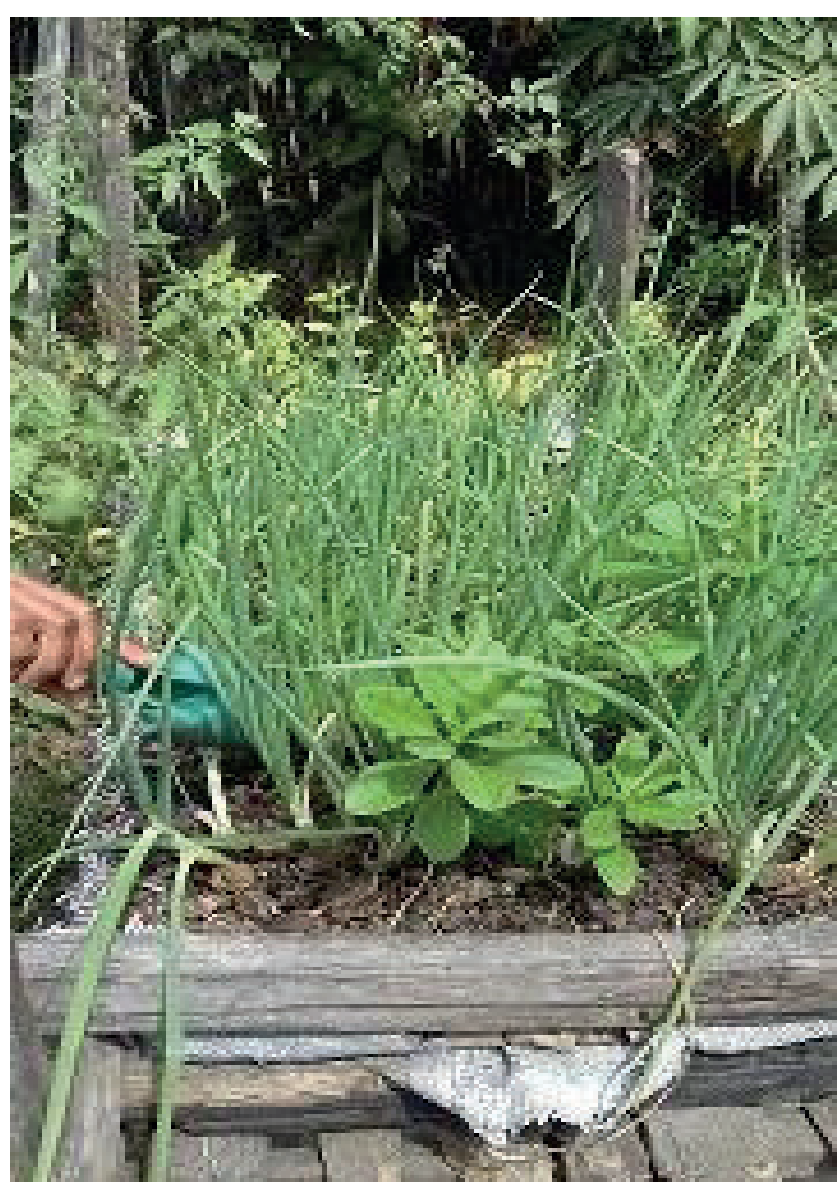

Figura 11- Utilização do adubo na horta domiciliar Fonte: Dados da pesquisa, 2019.

Dessa maneira, após a utilização do composto orgânico na adubação da horta domiciliar durante alguns dias, observou-se um maior desenvolvimento das plantas e hortaliças, constatando assim, a eficiência e qualidade do adubo orgânico gerado no desenvolvimento do projeto.

\section{CONSIDERAÇÕES FINAIS}

Os resíduos orgânicos, que representam cerca de $50 \%$ dos resíduos urbanos gerados no Brasil, tem a particularidade de poderem ser reciclados por meio de processos como a compostagem, em qualquer escala, desde a doméstica até a industrial. A problemática da disposição dos resíduos orgânicos domésticos atinge todas as sociedades, uma vez que, no Brasil a coleta seletiva não possui prática na implantação. 
Dessa maneira, a partir dos resultados obtidos fica evidente que a premissa que todos podem contribuir de maneira individual para as problemáticas relacionadas ao meio ambiente é verdadeira. A confecção da composteira foi através de materiais simples e de fácil acesso, com instruções de fácil compreensão, onde todas as etapas podem ser atingidas em um período de tempo curto. $A$ manutenção da composteira também não envolve grandes demandas físicas ou financeiras.

A principal dificuldade encontrada na implantação da composteira foi a falta de afinidade com a segregação de resíduos molhados (orgânicos) dos secos, uma vez que, alguns dias essa separação não era realizada por os moradores da residência não lembrarem da composteira. Assim, nota-se que a implantação de um projeto como este necessita está em conjunto com um rigoroso trabalho de educação ambiental, onde os indivíduos percebam a necessidade e importância do que estão sendo convidados a fabricar e implementar.

Diante do exposto, tem-se a compostagem como uma alternativa de tratamento a ser considerada para a reciclagem de resíduos orgânicos, pois, reduz consideravelmente a destinação inadequada desses materiais. Além disso, estimula a construção de horta dentro dos domicílios incentivando assim, a geração da produção e consumo de alimentos saudáveis. Uma vez que plantios feitos com adubo orgânico possuem melhor desenvolvimento, e muitos estudos comprovam sua melhor eficiência energética.

\section{REFERÊNCIAS}

AMORIM, V. F.; GARCIA, N. L.; SILVA, F. L. da. SILVA, M. T. da. OLIVEIRA, R. F. Vermicompostagem doméstica como alternativa na decomposição de resíduos orgânicos. 10 Simpósio Internacional de Qualidade Ambiental. Porto Alegre, 2016. Disponível em: <http:// www.abes-rs.uni5.net/centraldeeventos/_arqTrabaIhos/trab_20160929194143000000987.pdf>. Acesso em 13 de set. de 2019.

ANDREOLI, C. V.; ANDREOLI, F. de N.; TRINDADE, T. V.; HOPPEN, C. Resíduos sólidos: origem, classificação e soluções para destinação final adequada. Paraná:

Coleção Angrinho, 2014. Disponível em: <http:// www.agrinho.com.br/site/wpcontent/uploads/2014/09/32_Residuos- solidos.pdf $>$. Acesso em: 19 de abril de 2019.

BENTO, G. A. P. Manual de vermicompostagem - raspas e restos fazem a diferença. Universidade Federal do Paraná. Programa de Desenvolvimento Educacional. Curitiba, 2013. Disponível em: <http://www.educacao.
pr.gov.br/arquivos/File/Nossa_Escola/manual_vermicultura.pdf $>$. Acesso em 13 de maio de 2019. BRASIL. Lei n 12.305, de 2 de agosto de 2010. Institui a Política Nacional de Resíduos Sólidos; altera a Lei no 9.605, de 12 de fevereiro de 1998; e dá outras providências. Diário Oficial da União. Brasília, DF, 3 ago. 2010. Seção 1, p. 3.

BRASIL. Ministério do Meio Ambiente. Compostagem doméstica, comunitária e institucional de resíduos orgânicos: manual de orientação / Ministério do Meio Ambiente, Centro de Estudos e Promoção da Agricultura de Grupo, Serviço Social do Comércio. Brasília, DF: MMA, 2017. Disponível em: <http://www.mma.gov.br/images/arquivo/80058/ Compostagem- ManualOrientacao_MMA_2017-0620.pdf>. Acesso em 19 abr. 2019.

CHAN, Y.C.; SINHA, R.K.; WANG, W. J. Emission of greenhouse gases from home aerobic composting, anaerobic digestion and vermicomposting of household wastes in Brisbane (Australia). Waste Manag. Res., v. 29, pp. 540-548, 2010.

COSTA, A. T. da.; MANCA, R. da. S. Avaliação da eficiência de composto orgânico produzido a partir de composteira doméstica. Disponível em: <https://semanaacademica.org.br/system/files/artigos/artigo_-manca_e_costa.pdf $>$. Acesso em 19 de Abri. de 2019.

Empresa Brasileira de Pesquisa AgropecuáriaEMBRAPA. Ministério da Agricultura, Pecuária e Abastecimento. Como montar uma composteira caseira. Disponível em: <https://ainfo.cnptia.embrapa. br/digital/bitstream/item/136838/1/CPAF-AP- FolderCOMPOSTEIRA.pdf >. Acesso em 15 de maio de 2019. FERREIRA, Aline Guterres; BORBA, Sílvia Naiara de Souza; WIZNIEWSKY, José Geraldo. A prática da compostagem para a adubação orgânica pelos agricultores familiares de Santa Rosa/RS. Revista Eletrônica do Curso de Direito da UFSM, Santa Maria, RS, v. 8, p. 307317, abr. 2013. ISSN1981-3694. Disponível em: <https:// periodicos.ufsm.br/revistadireito/article/view/8275>. Acesso em 19 abr. 2019.

FILHO, D. L. M. et al. Gerenciamento de Resíduos em estabelecimentos alimentícios. Unicamp- Faculdade de Engenharia Mecânica. Disponível em: <http:// www.ib.unicamp.br/dep_biologia_animal/sites/www. ib.unicamp.br.site.dep_biologia_animal/files/8.\%20 GERENCIAMENTO\%20DE\%20RES\%C3\%8DDUOS\%20 Ali mentos.pdf >. Acesso em 10 de março de 2019. MELO, S. M. de. Análise do uso da compostagem domésticas em conjuntos habitacionais de interesse social 
na cidade de São Domingos - BAHIA. Universidade Federal da Bahia. Dissertação de Mestrado. Bahia, 2014. Disponível em: https:<//repositorio.ufba.br/ri/bitstream/ri/17374/1/Avalia\%C3\%A7\%C3\%A3o\%20do\%20 uso $\% 20$ de $\% 20$ compostagem $\% 20$ dom $\%$ C3\%A9stica\%20em\%20conjuntos\%20habit.pdf>. Acesso em 18 de Abril de 2019.

Ministério do Meio Ambiente. Lixo: um grave problema no mundo moderno. Brasília, D F : M M A, 2013. Disponível em: <http://www.mma.gov. br/estruturas/secex_consumo/_arquivos/8\%20-\%20 mcs_lixo.pdf>. Acesso em 18 de abril de 2019.

OLIVEIRA, A. et al, 2005. Compostagem Caseira de Lixo Orgânico Doméstico. Disponível em: <http://www. cnpmf.embrapa.br/publicacoes/circulares/circular_76. pdf>. Acesso em 10 de março de 2019.

OLIVEIRA, C.; FERNADES, J. Manual de compostagem doméstica com minhocas. Editora Egito Comercial. São Paulo, 2018. Disponível em: <http://web-resol. org/cartilhas/manual-composteira-minhocario.pdf>. Acesso em 13 de maio de 2019.

SARTORI, V. C. et al, (2012). Cartilha para Agricultores: Compostagem produção de fertilizantes a partir de resíduos orgânicos. Universidade de Caxias do Sul (UCS) 18. Centro de Ciências Agrárias e Biológicas. Disponível em: <https://www.ucs.br/site/midia/arquivos/cartilha-agricultores-compostagem.pdf $>$. Acesso em 24 de maio de 2019.

Serviço Nacional de Aprendizagem Industrial - SENAI. Compostagem de Resíduos Orgânicos - Plano de Gerenciamento de Resíduos Sólidos. Faculdade de Senai Fatesg. Goiânia, 2017. Disponível em: <https:// www.senaigo.com.br/repositoriosites/repositorio/ senai/editor/Image/PGRS_Compostagem_Residuos_ Organicos.pdf>. Acesso em 13 de set. de 2019.

SILVA, V. B. da. Compostagem orgânica - solução para lixo doméstico. Universidade Cândido Mendes. Pós Graduação em Planejamento e Educação Ambiental. Rio de Janeiro, 2003. Disponível em: <https://www.avm.edu.br/monopdf/26/VANDILENE\%20 BARRETO\%20DA\%20SILVA.pdf>. Acesso em 13 de ago. de 2019.

WAGEN, D. R. B.; FREITAS, I. C. V. Compostagem doméstica: alternativas de aproveitamento de resíduos sólidos orgânicos. Revista Brasileira de Agro ecologia, V. 5, n. 2, pag. 81-88, 2010. Disponível em: <http://orgprints. org/24494/1/Wangen_Compostagem.pdf $>$. Acesso em 13 de ago. de 2019.

\section{AUTORES}

ORCID: https://orcid.org/0000-0003-4395-2389

PALOMA DAYCY MENDES SILVA | Faculdade Pitágoras. Engenharia Ambiental. | São Luís, Maranhão - Brasil. Correspondência para: Rua Peru, Quadra 22, casa 17 - Sol e Mar, São Luís - MA. | e-mail: palomadaycy@gmail.com.

ORCID: https://orcid.org/0000-0003-1024-3607

MARILENA CHAVES SILVA | Faculdade Pitágoras. | Engenharia Ambiental.|São Luís, Maranhão-Brasil.|Correspondência para: Rua Projetada, Condomínio Marcelle 1, Bloco 10 Turu, São Luís - MA | e-mail: marilennachaves@gmail.com.

ORCID: https://orcid.org/0000-0001-5073-1643

SCARLETH KAROLYNE VIEIRA LEITÃO |Faculdade Pitágoras. Engenharia Ambiental. | São Luís, Maranhão - Brasil. | Correspondência para: Rua Doutor José Murta, n 550 - Alemanha, São Luís - MA | e-mail: carleth_vieira06@ outlook.com.

\section{ORCID: https://orcid.org/0000-0003-4612-7675}

ANA VALÉRIA PIRES MUNIZ | Faculdade Pitágoras. Engenharia Ambiental. | São Luís, Maranhão - Brasil. Correspondência para: Rua Mendes Frota, 17 - Olho d'água, São Luís - MA. e-mail: a.valeriamuniz@hotmail.com.

\section{COMO CITAR ESTE ARTIGO}

SILVA, Paloma Daycy Mendes; SILVA, Marilena Chaves; LEITÃO, Scarleth Karolyne Vieira; MUNIZ, Ana Valéria Pires. O Uso de Compostagem Doméstica na Produção de Adubo para Hortas Domiciliares. MIX Sustentável, [S.I.], v. 5, n. 4, p. 63-70, out. 2019. ISSN 24473073. Disponível em:<http://www.nexos.ufsc.br/index.php/ mixsustentavel>. Acesso em: dia mês. ano. doi:https:// doi.org/10.29183/2447-3073.MIX2019.v5.n4.63-70.

DATA DE ENVIO: 01/08/2019

DATA DE ACEITE: 03/10/2019 